\title{
Article \\ The Improved Element-Free Galerkin Method for 3D Helmholtz Equations
}

\author{
Heng Cheng ${ }^{1, *}$ and Miaojuan Peng ${ }^{2}$ \\ 1 School of Applied Science, Taiyuan University of Science and Technology, Taiyuan 030024, China \\ 2 Department of Civil Engineering, School of Mechanics and Engineering Science, Shanghai University, \\ Shanghai 200444, China; mjpeng@shu.edu.cn \\ * Correspondence: chengheng@shu.edu.cn; Tel.: +86-178-3511-1258
}

Citation: Cheng, H.; Peng, M. The Improved Element-Free Galerkin

Method for 3D Helmholtz Equations. Mathematics 2022, 10, 14. https:// doi.org/10.3390/math10010014

Academic Editors: Fernando Simões and Petr Knobloch

Received: 10 October 2021

Accepted: 29 November 2021

Published: 21 December 2021

Publisher's Note: MDPI stays neutral with regard to jurisdictional claims in published maps and institutional affiliations.

Copyright: (c) 2021 by the authors Licensee MDPI, Basel, Switzerland. This article is an open access article distributed under the terms and conditions of the Creative Commons Attribution (CC BY) license (https:// creativecommons.org/licenses/by/ $4.0 /)$.

\begin{abstract}
The improved element-free Galerkin (IEFG) method is proposed in this paper for solving 3D Helmholtz equations. The improved moving least-squares (IMLS) approximation is used to establish the trial function, and the penalty technique is used to enforce the essential boundary conditions. Thus, the final discretized equations of the IEFG method for 3D Helmholtz equations can be derived by using the corresponding Galerkin weak form. The influences of the node distribution, the weight functions, the scale parameters of the influence domain, and the penalty factors on the computational accuracy of the solutions are analyzed, and the numerical results of three examples show that the proposed method in this paper can not only enhance the computational speed of the element-free Galerkin (EFG) method but also eliminate the phenomenon of the singular matrix.
\end{abstract}

Keywords: improved element-free Galerkin method; Helmholtz equation; penalty method; improved moving least-squares approximation

\section{Introduction}

As an important elliptic differential equation, the Helmholtz equation has been widely applied in many different fields, such as mechanics, acoustics, physics, electromagnetics, engineering, and so on. It is well known that how to achieve the numerical solutions of Helmholtz equations effectively and accurately is one of the important directions in the scientific research.

Currently, many meshless methods have been used for researching Helmholtz equations, such as the element-free Galerkin (EFG) method [1], meshless Galerkin least-square method [2], meshless hybrid boundary-node method [3], boundary element-free method [4], and complex variable boundary element-free method $[5,6]$. Compared to the traditional finite difference method [7-10] and the finite element method, meshless methods [11-15] are based on scattered point approximation, which can avoid the mesh reconstruction, and thus a higher accuracy of the numerical solutions can be obtained.

As an important meshless method, the EFG method [16] was studied by Belytschko et al. In this method, a trial function is established by using the moving least-squares (MLS) approximation. Cheng et al. analyzed the error estimates of EFG method for potential problems [17]. Because the MLS approximation is based on the least-squares method [18-22], the disadvantages of the least-squares method also exist in the MLS approximation, in which sometimes ill-conditional or singular matrices occur.

In order to eliminate the singular matrices, the improved moving least-squares (IMLS) approximation [23] was proposed by Cheng et al., in which the orthogonal function system with a weight function is used as basis function, and thus can make up for the deficiency of the MLS approximation and has greater computational efficiency, using the IMLS approximation to establish the trial function. Thus, the improved element-free Galerkin (IEFG) method was applied for potential [24], transient heat conduction problems [25], the wave equation [26], the Schrödinger equation [27], advection-diffusion [28], elastodynamics [29], 
elastoplasticity [30], viscoelasticity [31], and diffusional drug release [32] problems. From these studies, we can see that under similar computational accuracy, the IEFG method has higher computational speed than the EFG method. As we know, meshless methods are based on node approximation without mesh reconstruction. When solving large deformation problems and dynamic propagation of cracks, the meshless method can obtain greater precision than the finite element method. In order to take advantage of the IEFG method further, Zhang et al. [33] developed the enriched IEFG method to solve 2D fracture problems. In this method, the enriched basis function is used at the tip of the crack. As a result, the singularity of the stresses at the tip of the crack can be shown better than in the IEFG method. Cai et al. [34] used the IEFG method for solving large elastoplasticity deformation problems. Three numerical examples are given to show that the numerical solutions are in good agreement with the solutions of finite element method software ANASYS and can enhance the computational efficiency of the EFG method.

By introducing the singular weight function into the MLS approximation, Lancaster et al. presented an interpolating MLS method [35]. The boundary conditions could be enforced directly in the corresponding meshless method. Based on the concept of an inner production, Ren et al. improved the interpolating MLS method [36] by using the singular weight function in interpolating points and orthogonalizing some of the base functions. Thus, the corresponding interpolating EFG method was presented for potential [37], transient heat conduction [38], and some mechanics [39-41] problems. Compared with the traditional EFG method, the interpolating EFG method has higher computational efficiency. Additionally, the interpolating smoothed particle method was developed by Qin et al. [42].

Using the nonsingular weight function, Wang et al. developed the improved interpolating MLS method [43], which can overcome the difficulties caused by the singular weight function in the interpolating MLS method, and used this method to construct the trial function. The improved interpolating EFG method was presented for potential [43] and several large deformation problems [44-46].

Based on the approximation of the vector function, the complex variable moving least-squares (CVMLS) approximation was presented by Cheng et al. [47]. Based on the CVMLS approximation and Galerkin weak form, the complex variable element-free Galerkin (CVEFG) method [48] was presented. Moreover, based on the conjugate basis function, Bai et al. proposed the improved CVMLS approximation to construct the shape function, and the improved CVEFG method was presented for elasticity problems [49]. The improved CVEFG method has higher computational accuracy and efficiency than the EFG method, but it cannot be applied to 3D problems directly because the complex theory is used. Chen et al. [50,51] proposed the complex variable reproducing kernel particle method.

By combining meshless methods and the finite difference method, the hybrid CVEFG method [52-56], dimension-splitting EFG method [57-60], dimension-splitting reproducing kernel particle method [61-64], interpolating dimension-splitting EFG method [65] and hybrid generalized interpolated EFG method [66] were proposed. These methods can greatly improve the computational efficiency of the traditional meshless method for solving multi-dimensional problems.

The IEFG method has some advantages over the traditional EFG method, such as higher computational efficiency, avoiding matrix inversion, and eliminating singular matrix. Therefore, it has been applied to many science and engineering problems. However, 3D Helmholtz equations have not been studied by the IEFG method yet, and the corresponding parameters cannot be discussed; thus, the computational accuracy and efficiency of the IEFG method for 3D Helmholtz equations are also uncertain. In order to overcome the disadvantage of the lower efficiency of the EFG method, this paper presents the IEFG method for solving 3D Helmholtz equations. The trial function was established by using the IMLS approximation, using the penalty technique to enforce the essential boundary conditions. The final discretized equations could be derived by using the corresponding weak form. Thus, we obtained the final formulate of the IEFG method for 3D Helmholtz equations. 
In Section 4, the influences of the node distribution, the weight functions, the scale parameters, and the penalty factors on the computational accuracy of the solutions are analyzed by giving examples. It is shown that the IEFG method for Helmholtz equations is convergent. Compared with the EFG method, the IEFG method has greater computational speed. Moreover, the singular matrix can be eliminated.

\section{The IMLS Approximation}

The approximation of a function $u(x)$ is

$$
u^{h}(\boldsymbol{x})=\sum_{i=1}^{m} p_{i}(\boldsymbol{x}) \cdot a_{i}(\boldsymbol{x})=\boldsymbol{p}^{\mathrm{T}}(\boldsymbol{x}) \cdot \boldsymbol{a}(\boldsymbol{x}),(\boldsymbol{x} \in \Omega),
$$

where $\boldsymbol{p}^{\mathrm{T}}(\boldsymbol{x})$ is the basis function vector, $m$ is the basis function number, and

$$
\boldsymbol{a}^{\mathrm{T}}(\boldsymbol{x})=\left(a_{1}(\boldsymbol{x}), a_{2}(\boldsymbol{x}), \cdots, a_{m}(\boldsymbol{x})\right)
$$

is the coefficient vector of $\boldsymbol{p}^{\mathrm{T}}(\boldsymbol{x})$.

In general,

$$
\begin{gathered}
\boldsymbol{p}^{\mathrm{T}}(\boldsymbol{x})=\left(1, x_{1}, x_{2}, x_{3}\right), \\
\boldsymbol{p}^{\mathrm{T}}(\boldsymbol{x})=\left(1, x_{1}, x_{2}, x_{3}, x_{1}^{2}, x_{2}^{2}, x_{3}^{2}, x_{1} x_{2}, x_{2} x_{3}, x_{1} x_{3}\right) .
\end{gathered}
$$

The local approximation is

$$
u^{h}(\boldsymbol{x}, \hat{\boldsymbol{x}})=\sum_{i=1}^{m} p_{i}(\hat{\boldsymbol{x}}) \cdot a_{i}(\boldsymbol{x})=\boldsymbol{p}^{\mathrm{T}}(\hat{\boldsymbol{x}}) \cdot \boldsymbol{a}(\boldsymbol{x}) .
$$

Define

$$
J=\sum_{I=1}^{n} w\left(\boldsymbol{x}-\boldsymbol{x}_{I}\right)\left[u^{h}\left(\boldsymbol{x}, \boldsymbol{x}_{I}\right)-u_{I}\right]^{2}=\sum_{I=1}^{n} w\left(\boldsymbol{x}-\boldsymbol{x}_{I}\right)\left[\sum_{i=1}^{m} p_{i}\left(\boldsymbol{x}_{I}\right) \cdot a_{i}(\boldsymbol{x})-u_{I}\right]^{2},
$$

where $w\left(x-x_{I}\right)$ is a weighting function, and $x_{I}(I=1,2, \cdots, n)$ are the nodes with influence domains covering point $x$.

Equation (6) can be written as

$$
J=(P \boldsymbol{a}-\boldsymbol{u})^{\mathrm{T}} \boldsymbol{W}(\boldsymbol{x})(\boldsymbol{P} \boldsymbol{a}-\boldsymbol{u}),
$$

where

$$
\begin{gathered}
\boldsymbol{u}^{\mathrm{T}}=\left(u_{1}, u_{2}, \cdots, u_{n}\right) \\
\boldsymbol{P}=\left[\begin{array}{cccc}
p_{1}\left(x_{1}\right) & p_{2}\left(x_{1}\right) & \cdots & p_{m}\left(x_{1}\right) \\
p_{1}\left(x_{2}\right) & p_{2}\left(x_{2}\right) & \cdots & p_{m}\left(x_{2}\right) \\
\vdots & \vdots & \ddots & \vdots \\
p_{1}\left(x_{n}\right) & p_{2}\left(x_{n}\right) & \cdots & p_{m}\left(x_{n}\right)
\end{array}\right],
\end{gathered}
$$

and

$$
\mathbf{W}(\boldsymbol{x})=\left[\begin{array}{cccc}
w\left(x-x_{1}\right) & 0 & \cdots & 0 \\
0 & w\left(x-x_{2}\right) & \cdots & 0 \\
\vdots & \vdots & \ddots & \vdots \\
0 & 0 & \cdots & w\left(x-x_{n}\right)
\end{array}\right]
$$

From

$$
\frac{\partial J}{\partial \boldsymbol{a}}=A(x) \boldsymbol{a}(\boldsymbol{x})-\boldsymbol{B}(\boldsymbol{x}) \boldsymbol{u}=0,
$$

we have

$$
A(x) a(x)=B(x) u,
$$


where

$$
\begin{gathered}
\boldsymbol{A}(\boldsymbol{x})=\boldsymbol{P}^{\mathrm{T}} \boldsymbol{W}(\boldsymbol{x}) \boldsymbol{P}, \\
\boldsymbol{B}(\boldsymbol{x})=\boldsymbol{P}^{\mathrm{T}} \boldsymbol{W}(\boldsymbol{x}) .
\end{gathered}
$$

Equation (12) sometimes forms a singular or ill-conditional matrix. In order to make up for this deficiency, for basis functions

$$
\boldsymbol{q}=\left(q_{i}\right)=\left(1, x_{1}, x_{2}, x_{3}, x_{1}^{2}, x_{2}^{2}, x_{3}^{2}, x_{1} x_{2}, x_{2} x_{3}, x_{3} x_{1}, \cdots\right),
$$

using the Gram-Schmidt process, we can obtain

$$
p_{i}=q_{i}-\sum_{k=1}^{i-1} \frac{\left(q_{i}, p_{k}\right)}{\left(p_{k}, p_{k}\right)} p_{k},(i=1,2,3, \cdots),
$$

and

$$
\left(p_{i}, p_{j}\right)=0,(i \neq j) .
$$

Then, from Equation (12), $a(\boldsymbol{x})$ can be obtained as

$$
a(x)=A^{*}(x) B(x) u,
$$

where

$$
A^{*}(\boldsymbol{x})=\left[\begin{array}{cccc}
\frac{1}{\left(p_{1}, p_{1}\right)} & 0 & \cdots & 0 \\
0 & \frac{1}{\left(p_{2}, p_{2}\right)} & 0 & 0 \\
\vdots & \vdots & \ddots & \vdots \\
0 & 0 & \cdots & \frac{1}{\left(p_{n}, p_{n}\right)}
\end{array}\right]
$$

Substituting Equation (18) into Equation (5), we have

$$
u^{h}(\boldsymbol{x})=\boldsymbol{\Phi}^{*}(\boldsymbol{x}) u=\sum_{I=1}^{n} \boldsymbol{\Phi}_{I}^{*}(\boldsymbol{x}) u_{I}
$$

where

$$
\boldsymbol{\Phi}^{*}(x)=\left(\boldsymbol{\Phi}_{1}^{*}(x), \boldsymbol{\Phi}_{2}^{*}(x), \cdots, \boldsymbol{\Phi}_{n}^{*}(x)\right)=p^{\mathrm{T}}(x) A^{*}(x) B(x)
$$

is the shape function.

This is the IMLS approximation [23], in which the shape function can be obtained more easily than the MLS approximation. Moreover, the IMLS approximation can also avoid the singular matrix. Thus, it can enhance the computational efficiency of the MLS approximation.

\section{The IEFG Method for 3D Helmholtz Equations}

The governing equation is

$$
\Delta u+k^{2} u=f(x),\left(x=\left(x_{1}, x_{2}, x_{3}\right) \in \Omega\right)
$$

and the boundary conditions are

$$
\begin{gathered}
u(x)=\bar{u},\left(x \in \Gamma_{u}\right), \\
q(x)=\frac{\partial u(x)}{\partial x_{1}} n_{1}+\frac{\partial u(x)}{\partial x_{2}} n_{2}+\frac{\partial u(x)}{\partial x_{3}} n_{3}=\bar{q},\left(x \in \Gamma_{q}\right),
\end{gathered}
$$

where $k^{2}$ is the wave number, $f(x)$ is the given function, $\bar{u}$ and $\bar{q}$ are the given values, and $\Gamma=\Gamma_{u} \cup \Gamma_{q}, \Gamma_{u} \cap \Gamma_{q}=\varnothing, n_{i}(i=1,2,3)$ is the unit outward normal to the boundary $\Gamma$ in direction $x_{i}$. 
For 3D Helmholtz equations, the equivalent functional is

$$
\Pi=\int_{\Omega} u\left(\frac{1}{2} k^{2} u-f\right) \mathrm{d} \Omega-\int_{\Omega} \frac{1}{2}\left[\left(\frac{\partial u}{\partial x_{1}}\right)^{2}+\left(\frac{\partial u}{\partial x_{2}}\right)^{2}+\left(\frac{\partial u}{\partial x_{3}}\right)^{2}\right] \mathrm{d} \Omega-\int_{\Gamma_{q}} u \bar{q} \mathrm{~d} \Gamma .
$$

By introducing the penalty technique to apply the boundary conditions, we can obtain the modified functional

$$
\Pi^{*}=\Pi+\frac{\alpha}{2} \int_{\Gamma_{u}}(u-\bar{u})(u-\bar{u}) \mathrm{d} \Gamma,
$$

where $\alpha$ is the penalty factor.

Let

$$
\delta \Pi^{*}=0 .
$$

We can obtain the following equivalent integral weak form

$$
\begin{gathered}
\int_{\Omega} \delta u \cdot k^{2} u \mathrm{~d} \Omega-\int_{\Omega} \delta(\boldsymbol{L} u)^{\mathrm{T}} \cdot(\boldsymbol{L} u) \mathrm{d} \Omega-\int_{\Omega} \delta u \cdot f \mathrm{~d} \Omega-\int_{\Gamma_{q}} \delta u \cdot \bar{q} \mathrm{~d} \Gamma \\
+\alpha \int_{\Gamma_{u}} \delta u \cdot u \mathrm{~d} \Gamma-\alpha \int_{\Gamma_{u}} \delta u \cdot \bar{u} \mathrm{~d} \Gamma=0,
\end{gathered}
$$

where

$$
L(\cdot)=\left[\begin{array}{c}
\frac{\partial}{\partial x_{1}} \\
\frac{\partial}{\partial x_{2}} \\
\frac{\partial}{\partial x_{3}}
\end{array}\right](\cdot)
$$

In the cubic domain $\Omega$, we employ $M$ nodes $x_{I}(I=1,2, \cdots, M)$. Thus, we have

$$
u_{I}=u\left(x_{I}\right) .
$$

From the IMLS approximation, we can obtain

$$
u(\boldsymbol{x})=\boldsymbol{\Phi}^{*}(\boldsymbol{x}) \boldsymbol{u}=\sum_{I=1}^{n} \boldsymbol{\Phi}_{I}^{*}(\boldsymbol{x}) u_{I},
$$

where

$$
\boldsymbol{u}=\left(u_{1}, u_{2}, \cdots, u_{n}\right)^{\mathrm{T}} .
$$

From Equations (29) and (31), we have

$$
\boldsymbol{L} u(\boldsymbol{x})=\sum_{I=1}^{n}\left[\begin{array}{c}
\frac{\partial}{\partial x_{1}} \\
\frac{\partial}{\partial x_{2}} \\
\frac{\partial}{\partial x_{3}}
\end{array}\right] \boldsymbol{\Phi}_{I}^{*}(\boldsymbol{x}) u_{I}=\sum_{I=1}^{n} \boldsymbol{B}_{I} u_{I}=\boldsymbol{B}(\boldsymbol{x}) u,
$$

where

$$
\begin{gathered}
\boldsymbol{B}(\boldsymbol{x})=\left(\boldsymbol{B}_{1}, \boldsymbol{B}_{2}, \cdots, \boldsymbol{B}_{n}\right), \\
\boldsymbol{B}_{I}=\left[\begin{array}{l}
\boldsymbol{\Phi}_{I, 1}^{*}(\boldsymbol{x}) \\
\boldsymbol{\Phi}_{I, 2}^{*}(\boldsymbol{x}) \\
\boldsymbol{\Phi}_{I, 3}^{*}(\boldsymbol{x})
\end{array}\right] .
\end{gathered}
$$

Substituting Equations (31) and (33) into Equation (28), we have

$$
\begin{gathered}
\int_{\Omega} \delta\left[\boldsymbol{\Phi}^{*}(\boldsymbol{x}) \boldsymbol{u}\right]^{\mathrm{T}} \cdot k^{2} \cdot\left[\boldsymbol{\Phi}^{*}(\boldsymbol{x}) u\right] \mathrm{d} \Omega-\int_{\Omega} \delta[\boldsymbol{B}(\boldsymbol{x}) \boldsymbol{u}]^{\mathrm{T}}[\boldsymbol{B}(\boldsymbol{x}) u] \mathrm{d} \Omega \\
-\int_{\Gamma_{q}} \delta\left[\boldsymbol{\Phi}^{*}(\boldsymbol{x}) \boldsymbol{u}\right]^{\mathrm{T}} \cdot \bar{q} \mathrm{~d} \Gamma-\int_{\Omega} \delta\left[\boldsymbol{\Phi}^{*}(\boldsymbol{x}) \boldsymbol{u}\right]^{\mathrm{T}} \cdot f \mathrm{~d} \Omega \\
\alpha \int_{\Gamma_{u}} \delta\left[\boldsymbol{\Phi}^{*}(\boldsymbol{x}) \boldsymbol{u}\right]^{\mathrm{T}} \cdot\left[\boldsymbol{\Phi}^{*}(\boldsymbol{x}) u\right] \mathrm{d} \Gamma-\alpha \int_{\Gamma_{u}} \delta\left[\boldsymbol{\Phi}^{*}(\boldsymbol{x}) \boldsymbol{u}\right]^{\mathrm{T}} \cdot \bar{u} \mathrm{~d} \Gamma=0 .
\end{gathered}
$$

In Equation (36), the form of $u$ is the same as Equation (32), and $n=M$. 
All integral terms in Equation (36) are analyzed as follows:

$$
\begin{aligned}
& \int_{\Omega} \delta\left[\boldsymbol{\Phi}^{*}(\boldsymbol{x}) \boldsymbol{u}\right]^{\mathrm{T}} \cdot k^{2} \cdot\left[\boldsymbol{\Phi}^{*}(\boldsymbol{x}) \boldsymbol{u}\right] \mathrm{d} \Omega=\delta \boldsymbol{u}^{\mathrm{T}} \cdot k^{2}\left[\int_{\Omega} \boldsymbol{\Phi}^{* \mathrm{~T}}(\boldsymbol{x}) \boldsymbol{\Phi}^{*}(\boldsymbol{x}) \mathrm{d} \Omega\right] \cdot u, \\
& \int_{\Omega} \delta[\boldsymbol{B}(\boldsymbol{x}) \boldsymbol{u}]^{\mathrm{T}} \cdot[\boldsymbol{B}(\boldsymbol{x}) \boldsymbol{u}] \mathrm{d} \Omega=\delta \boldsymbol{u}^{\mathrm{T}} \cdot\left[\int_{\Omega} \boldsymbol{B}^{\mathrm{T}}(\boldsymbol{x}) \boldsymbol{B}(\boldsymbol{x}) \mathrm{d} \Omega\right] \cdot \boldsymbol{u}, \\
& \int_{\Omega} \delta\left[\boldsymbol{\Phi}^{*}(\boldsymbol{x}) \boldsymbol{u}\right]^{\mathrm{T}} \cdot f \mathrm{~d} \Omega=\delta \boldsymbol{u}^{\mathrm{T}} \cdot\left[\int_{\Omega} \boldsymbol{\Phi}^{* \mathrm{~T}}(\boldsymbol{x}) f \mathrm{~d} \Omega\right], \\
& \int_{\Gamma_{q}} \delta\left[\boldsymbol{\Phi}^{*}(\boldsymbol{x}) \boldsymbol{u}\right]^{\mathrm{T}} \cdot \bar{q} \mathrm{~d} \Gamma=\delta \boldsymbol{u}^{\mathrm{T}} \cdot\left[\int_{\Gamma_{q}} \boldsymbol{\Phi}^{* \mathrm{~T}}(\boldsymbol{x}) \bar{q} \mathrm{~d} \Gamma\right], \\
& \alpha \int_{\Gamma_{u}} \delta\left[\boldsymbol{\Phi}^{*}(\boldsymbol{x}) \boldsymbol{u}\right]^{\mathrm{T}} \cdot\left[\boldsymbol{\Phi}^{*}(\boldsymbol{x}) \boldsymbol{u}\right] \mathrm{d} \Gamma=\delta \boldsymbol{u}^{\mathrm{T}} \cdot\left[\alpha \int_{\Gamma_{u}} \boldsymbol{\Phi}^{* \mathrm{~T}}(\boldsymbol{x}) \boldsymbol{\Phi}^{*}(\boldsymbol{x}) \mathrm{d} \Gamma\right] \cdot \boldsymbol{u}, \\
& \alpha \int_{\Gamma_{u}} \delta\left[\boldsymbol{\Phi}^{*}(\boldsymbol{x}) \boldsymbol{u}\right]^{\mathrm{T}} \cdot \bar{u} \mathrm{~d} \Gamma=\delta \boldsymbol{u}^{\mathrm{T}} \cdot\left[\alpha \int_{\Gamma_{u}} \boldsymbol{\Phi}^{* \mathrm{~T}}(\boldsymbol{x}) \bar{u} \mathrm{~d} \Gamma\right] .
\end{aligned}
$$

Let

$$
\begin{gathered}
\boldsymbol{C}=k^{2} \int_{\Omega} \boldsymbol{\Phi}^{* \mathrm{~T}}(\boldsymbol{x}) \boldsymbol{\Phi}^{*}(\boldsymbol{x}) \mathrm{d} \Omega, \\
\boldsymbol{K}=\int_{\Omega} \boldsymbol{B}^{\mathrm{T}}(\boldsymbol{x}) \boldsymbol{B}(\boldsymbol{x}) \mathrm{d} \Omega, \\
\boldsymbol{F}_{1}=\int_{\Omega} \boldsymbol{\Phi}^{* \mathrm{~T}}(\boldsymbol{x}) f \mathrm{~d} \Omega, \\
\boldsymbol{F}_{2}=\int_{\Gamma_{q}} \boldsymbol{\Phi}^{* \mathrm{~T}}(\boldsymbol{x}) \bar{q} \mathrm{~d} \Gamma, \\
\boldsymbol{K}^{\alpha}=\alpha \int_{\Gamma_{u}} \boldsymbol{\Phi}^{* \mathrm{~T}}(\boldsymbol{x}) \boldsymbol{\Phi}^{*}(\boldsymbol{x}) \mathrm{d} \Gamma, \\
\boldsymbol{F}^{\alpha}=\alpha \int_{\Gamma_{u}} \boldsymbol{\Phi}^{* \mathrm{~T}}(\boldsymbol{x}) \bar{u} \mathrm{~d} \Gamma .
\end{gathered}
$$

Substituting Equations (37)-(42) into Equation (36), we can obtain

$$
\delta \boldsymbol{u}^{\mathrm{T}}\left(\boldsymbol{C} \boldsymbol{u}-\boldsymbol{K} \boldsymbol{u}-\boldsymbol{F}_{1}-\boldsymbol{F}_{2}-\boldsymbol{F}^{\alpha}+\boldsymbol{K}^{\alpha} \boldsymbol{u}\right)=0 .
$$

The $\delta \boldsymbol{u}^{\mathrm{T}}$ is arbitrary; thus we can obtain

$$
\widetilde{\boldsymbol{K}} u=\widetilde{\boldsymbol{F}},
$$

where

$$
\begin{gathered}
\widetilde{\boldsymbol{K}}=C-\boldsymbol{K}+\boldsymbol{K}^{\alpha}, \\
\widetilde{\boldsymbol{F}}=\boldsymbol{F}_{1}+\boldsymbol{F}_{2}+\boldsymbol{F}^{\alpha} .
\end{gathered}
$$

This is the IEFG method for 3D Helmholtz equations.

\section{Numerical Examples}

The formula of the relative error is

$$
\left\|u-u^{h}\right\|_{L^{2}(\Omega)}^{r e l}=\frac{\left\|u-u^{h}\right\|_{L^{2}(\Omega)}}{\|u\|_{L^{2}(\Omega)}},
$$

where

$$
\left\|u-u^{h}\right\|_{L^{2}(\Omega)}=\left(\int_{\Omega}\left(u-u^{h}\right)^{2} \mathrm{~d} \Omega\right)^{1 / 2}
$$


In order to illustrate the advantages of the IFFG method, we chose three examples from other literature. The nodes distributed in the problem domains of these numerical examples were regular, the linear basis function was selected, and $3 \times 3 \times 3$ Gaussian points were selected in each integral cell. The IEFG and the EFG methods are used to solve these examples.

The following equation is considered in the first example:

$$
\Delta u+u=\left(12 x_{1}^{2}-x_{1}^{4}\right) \sin x_{2} \cos x_{3} .
$$

The boundary conditions are

$$
\begin{gathered}
u\left(0, x_{2}, x_{3}\right)=0, \\
u\left(\pi, x_{2}, x_{3}\right)=\pi^{4} \sin x_{2} \cos x_{3}, \\
u\left(x_{1}, 0, x_{3}\right)=u\left(x_{1}, \pi, x_{3}\right)=0, \\
u\left(x_{1}, x_{2}, 0\right)=-u\left(x_{1}, x_{2}, \pi\right)=x_{1}^{4} \sin x_{2} .
\end{gathered}
$$

The problem domain is $\Omega=[0, \pi] \times[0, \pi] \times[0, \pi]$, and

$$
u=x_{1}^{4} \sin x_{2} \cos x_{3}
$$

is the analytical solution.

In order to study the convergence of the EFG and the IEFG methods for Helmholtz equations, all parameters of both methods were kept the same. The cubic spline weight functions were used, $d_{\max }=1.35, \alpha=2.0 \times 10^{4}$. Table 1 shows the relationship between relative errors and node distribution. It is shown that, with the increase in nodes, the precision of numerical solutions improves as well, but the computational efficiency is reduced gradually. Therefore, the two methods in this paper are convergent. Both the computational accuracy and efficiency are considered, and $15 \times 15 \times 15$ regularly distributed nodes are selected.

Table 1. Relative errors and CPU times of the improved element-free Galerkin (IEFG) and element-free Galerkin (EFG) methods with the increase in node distribution.

\begin{tabular}{ccccc}
\hline \multirow{2}{*}{ Nodes } & \multicolumn{2}{c}{ Relative Error } & \multicolumn{2}{c}{ Time (s) } \\
\cline { 2 - 5 } & IEFG & EFG & IEFG & EFG \\
\hline $7 \times 7 \times 7$ & $4.3092 \%$ & $4.3092 \%$ & 5.5 & 5.8 \\
$11 \times 11 \times 11$ & $1.3234 \%$ & $1.3234 \%$ & 26.7 & 28.5 \\
$13 \times 13 \times 13$ & $0.8832 \%$ & $0.8832 \%$ & 49.9 & 53.1 \\
$15 \times 15 \times 15$ & $0.6296 \%$ & $0.6296 \%$ & 92.1 & 98.0 \\
$17 \times 17 \times 17$ & $0.4706 \%$ & $0.4706 \%$ & 152.0 & 161.9 \\
$21 \times 21 \times 21$ & $0.2905 \%$ & $0.2905 \%$ & 384.5 & 398.6 \\
$25 \times 25 \times 25$ & $0.1967 \%$ & $0.1967 \%$ & 903.3 & 940.2 \\
$29 \times 29 \times 29$ & $0.1520 \%$ & $0.1520 \%$ & 1907.2 & 1937.1 \\
$33 \times 33 \times 33$ & $0.1075 \%$ & $0.1075 \%$ & 4287.2 & 4408.3 \\
\hline
\end{tabular}

The effects of the weight function, the scale parameter of the influence domain, and the penalty factor on solution of the IEFG method will be discussed.

\section{(1) Weight function}

When the cubic spline function is used, $15 \times 15 \times 15$ regularly distributed nodes and $14 \times 14 \times 14$ background integral cells are selected, $\alpha=2.0 \times 10^{4}, d_{\max }=1.35$. Thus, the smaller relative error is $0.6296 \%$. When the quartic spline function is used, and the same regularly distributed nodes and background integral grids are used, $\alpha=2.2 \times 10^{4}$, $d_{\max }=1.28$, the smaller relative error is $0.6274 \%$. It is shown that the similar relative errors can be obtained when using two weight functions. 
In addition, the singular matrix can be avoided in the IEFG method when using the cubic spline function. If $d_{\max }=1.0$, the quartic spline function is selected. Unfortunately, the singular matrix occurs and the final result cannot be obtained. When the cubic spline function is used, the relative error is $0.6451 \%$.

Thus, the cubic spline function is selected.

\section{(2) Scale parameter}

The same node distribution and background integral grids are selected, $\alpha=2.0 \times 10^{4}$, and the cubic spline function is used. Figure 1 shows the relationship between $d_{\max }$ and relative errors. Because of the error of computer itself, the relative error become larger when $d_{\max }=1.2$. It is shown that when $d_{\max }=1.35$, the relative error is smaller.

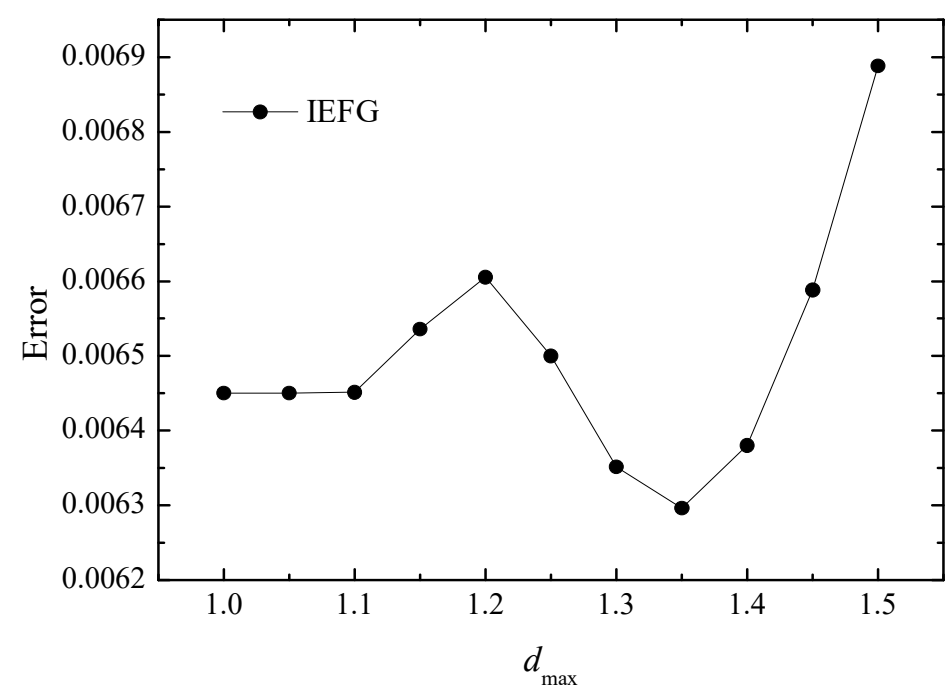

Figure 1. The error of the numerical solutions of the IEFG method with the increase in $d_{\max }$.

\section{(3) Penalty factor}

The same node distribution, background integral grids, and weight function are selected, $d_{\max }=1.35$. Figure 2 shows the relationship between $\alpha$ and relative errors. It is shown that when $\alpha=2.0 \times 10^{4}$, the relative error is smaller.

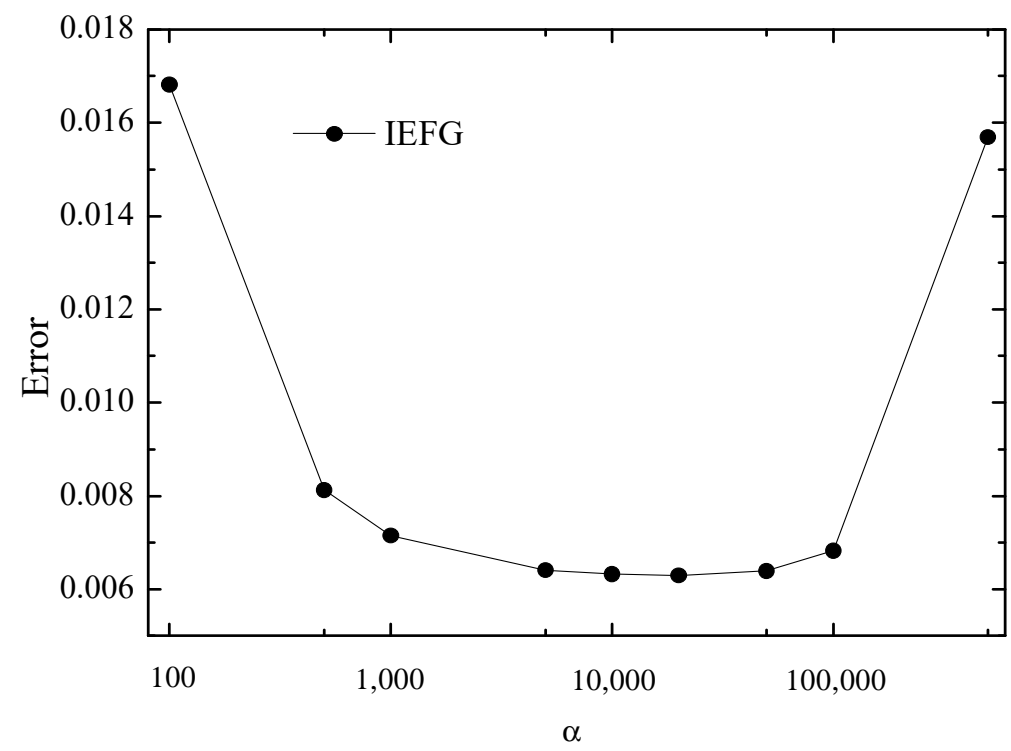

Figure 2. The error of the numerical solutions of the IEFG method with the increase in $\alpha$. 
The IEFG method is selected to solve it, $15 \times 15 \times 15$ regularly distributed nodes and $14 \times 14 \times 14$ background integral cells are selected, and the cubic spline function is used, $\alpha=2.0 \times 10^{4}, d_{\max }=1.35$. When using the EFG method to solve it, the same parameters are selected, and thus the relative errors of two methods are equal to $0.6296 \%$.

Figures 3-5 show the comparison between numerical solutions and analytical ones, and the CPU times of the IEFG method and the EFG method are $92.1 \mathrm{~s}$ and $98.0 \mathrm{~s}$, respectively. Obviously, higher computational efficiency can be obtained when using the IEFG method.

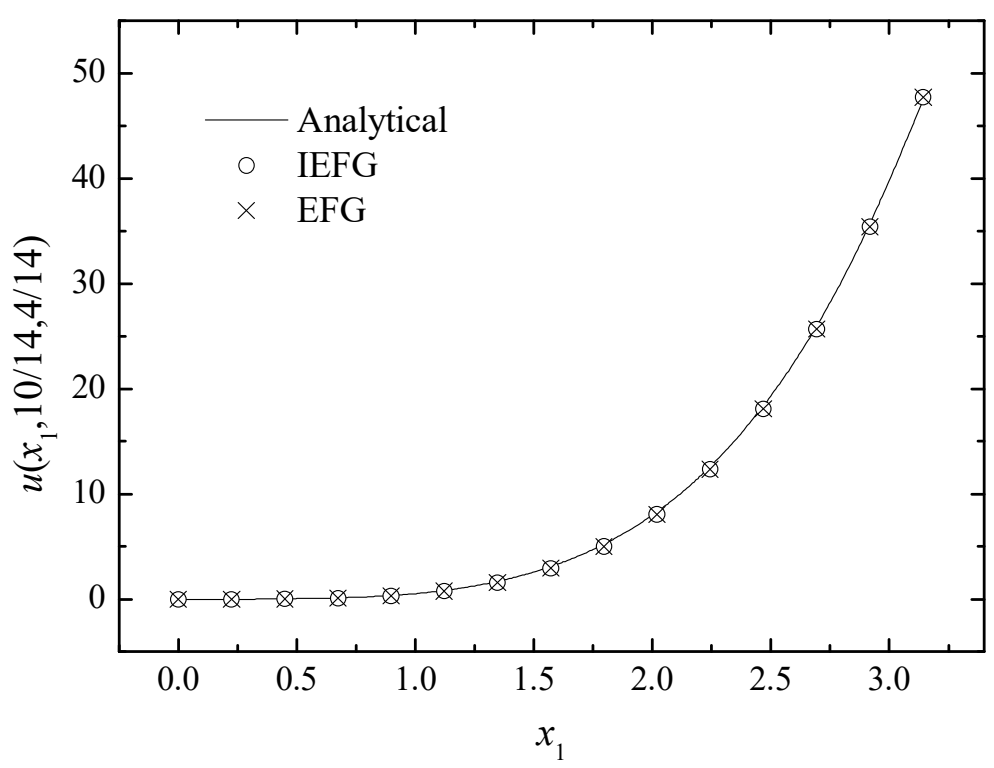

Figure 3. The comparison of the numerical and analytical solutions of the two methods along the $x_{1}$-axis.

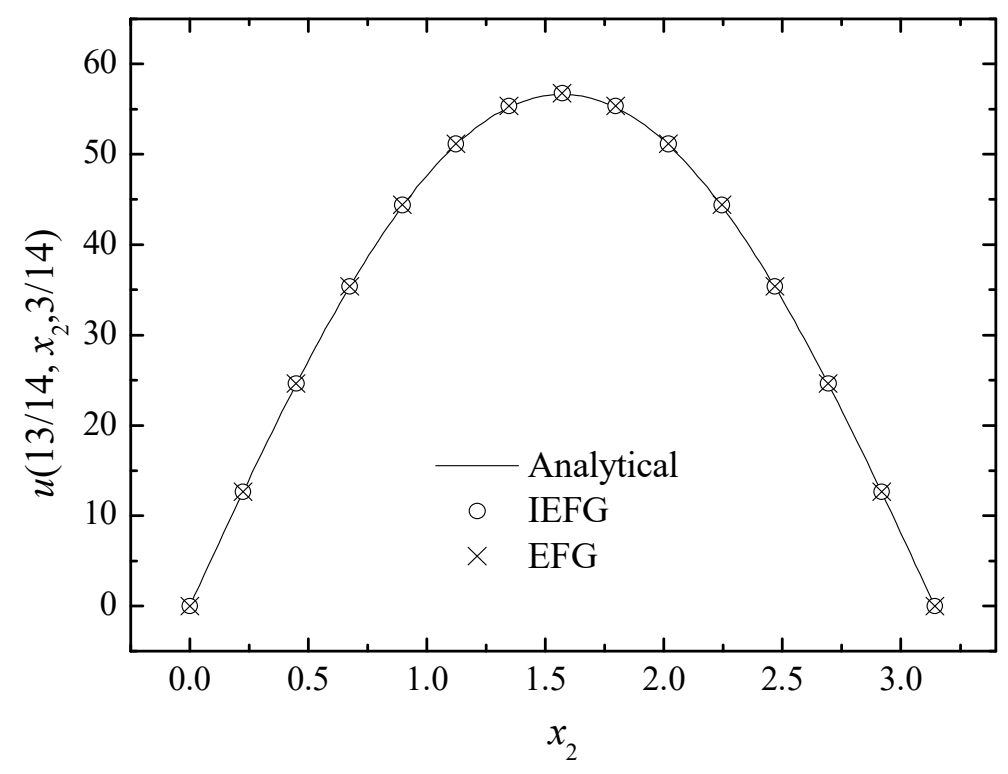

Figure 4. The comparison of the numerical and analytical solutions of the two methods along the $x_{2}$-axis. 


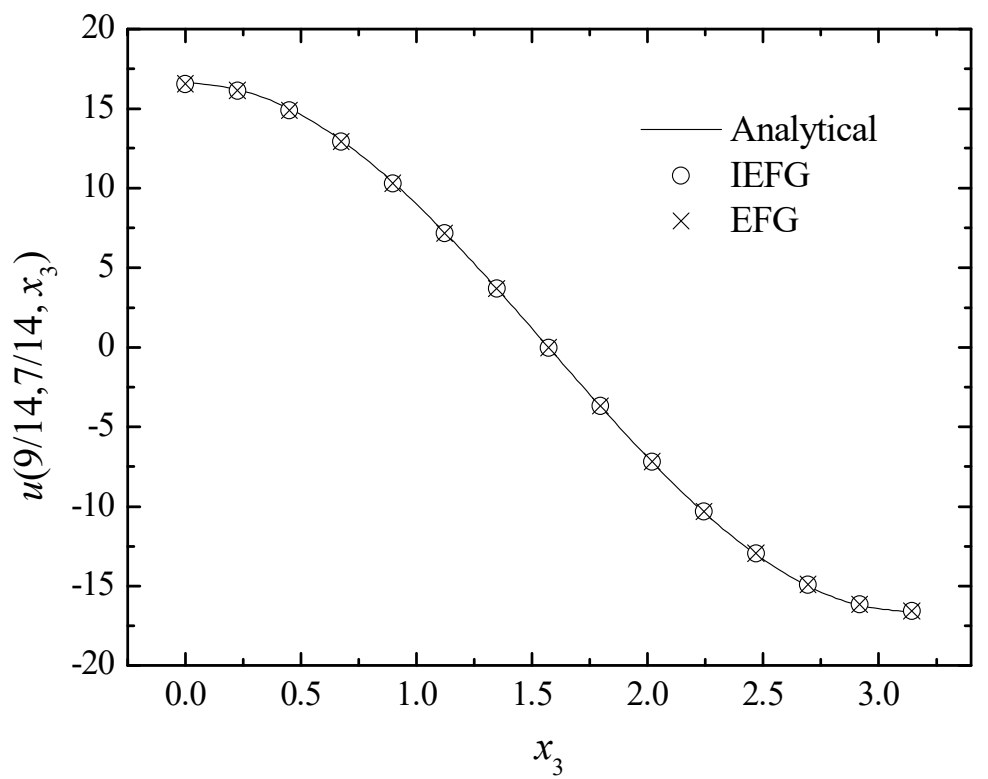

Figure 5. The comparison of the numerical and analytical solutions of the two methods along the $x_{3}$-axis.

Additionally, the singular matrix can be avoided when constructing the shape functions when the IEFG is used. If $d_{\max }=1.0$ and other parameters are the same, two methods are used to solve it, and two different results are obtained. When the EFG method is used, the singular matrix occurs and the final result cannot be obtained. However, using the IEFG method to solve it, the relative error of the numerical solutions is $0.6451 \%$. The numerical and analytical results are compared in Figure 6; it is shown that the numerical results are in good agreement with the analytical ones.

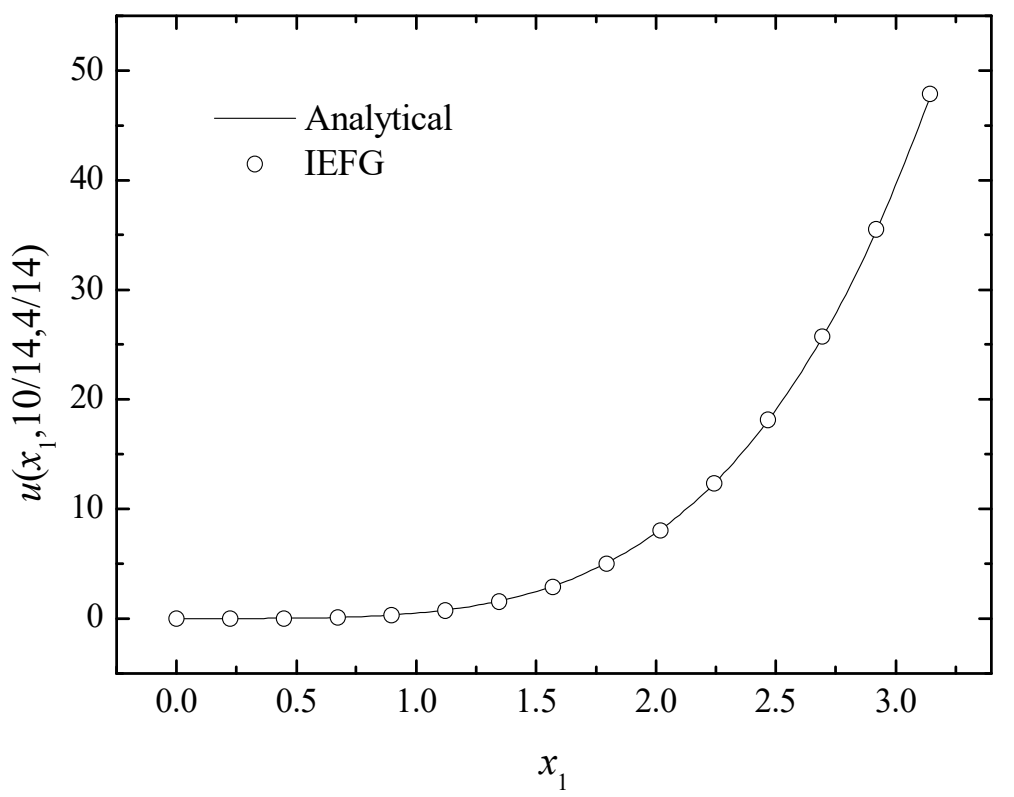

Figure 6. The numerical and analytical solutions of the IEFG method along the $x_{1}$-axis. 
The second example [67] is

$$
\Delta u-k^{2} u=0
$$

The boundary conditions are

$$
\begin{gathered}
u\left(0, x_{2}, x_{3}\right)=e^{\left(\xi_{2} x_{2}+\xi_{3} x_{3}\right)}, \\
u\left(1, x_{2}, x_{3}\right)=\left(\xi_{1}+\xi_{2} x_{2}+\xi_{3} x_{3}\right) \\
u\left(x_{1}, 0, x_{3}\right)=e^{\left(\xi_{1} x_{1}+\xi_{3} x_{3}\right)}, \\
u\left(x_{1}, 1, x_{3}\right)=e^{\left(\xi_{1} x_{1}+\xi_{2}+\xi_{3} x_{3}\right)}, \\
u\left(x_{1}, x_{2}, 0\right)=e^{\left(\xi_{1} x_{1}+\xi_{2} x_{2}\right)}, \\
u\left(x_{1}, x_{2}, 1\right)=e^{\left(\xi_{1} x_{1}+\xi_{2} x_{2}+\xi_{3}\right)} .
\end{gathered}
$$

The problem domain is $\Omega=[0,1] \times[0,1] \times[0,1]$, and

$$
u=e^{\left(\xi_{1} x_{1}+\xi_{2} x_{2}+\xi_{3} x_{3}\right)}
$$

is the analytical solution.

We set $k=2, \xi_{1}=1$, and $\xi_{2}=0.5$. The IEFG method is used to solve it, $\alpha=1.7 \times 10^{3}$, $d_{\max }=1.21$. The $15 \times 15 \times 15$ regularly distributed nodes and $14 \times 14 \times 14$ background integral grids are used. When using the EFG method to solve it, the same parameters are selected, and thus the same computational accuracy can be obtained. The relative errors of both methods are equal to $0.0844 \%$. Figures $7-9$ show the comparison of the numerical solutions of the two methods and the analytical ones. The CPU times of the IEFG method and the EFG method are $92.1 \mathrm{~s}$ and $98.0 \mathrm{~s}$, respectively. We can see that the computational results of both methods are in very good agreement with the analytical ones.

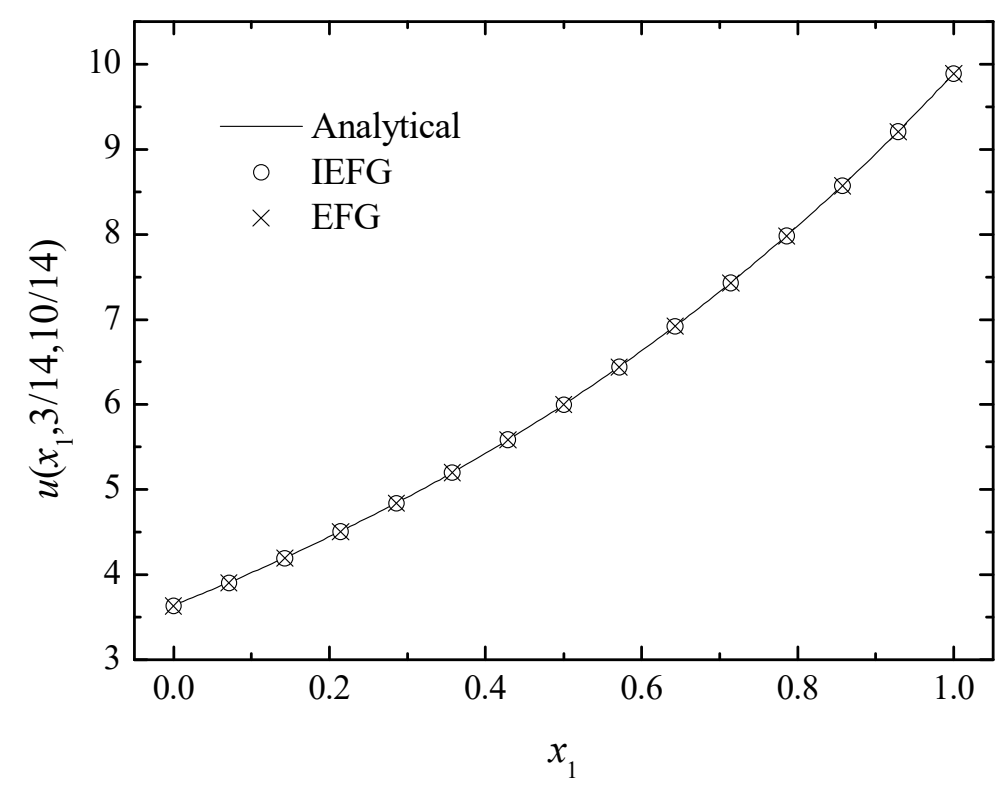

Figure 7. The comparison of the numerical and analytical solutions of the two methods along the $x_{1}$-axis. 


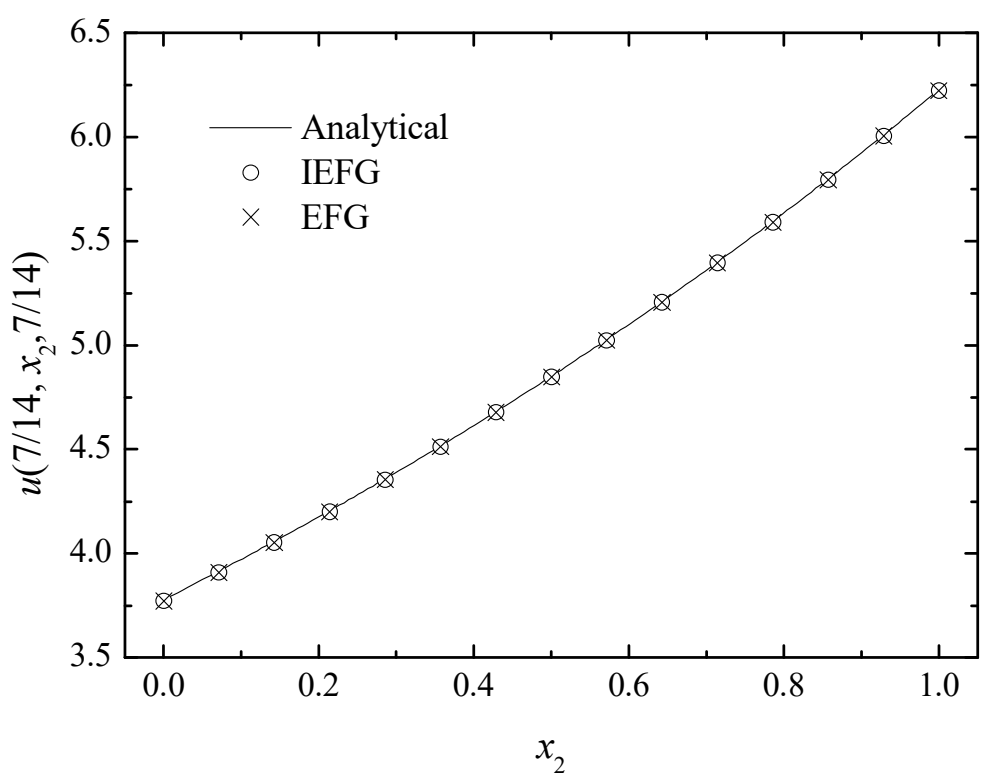

Figure 8. The comparison of the numerical and analytical solutions of the two methods along the $x_{2}$-axis.

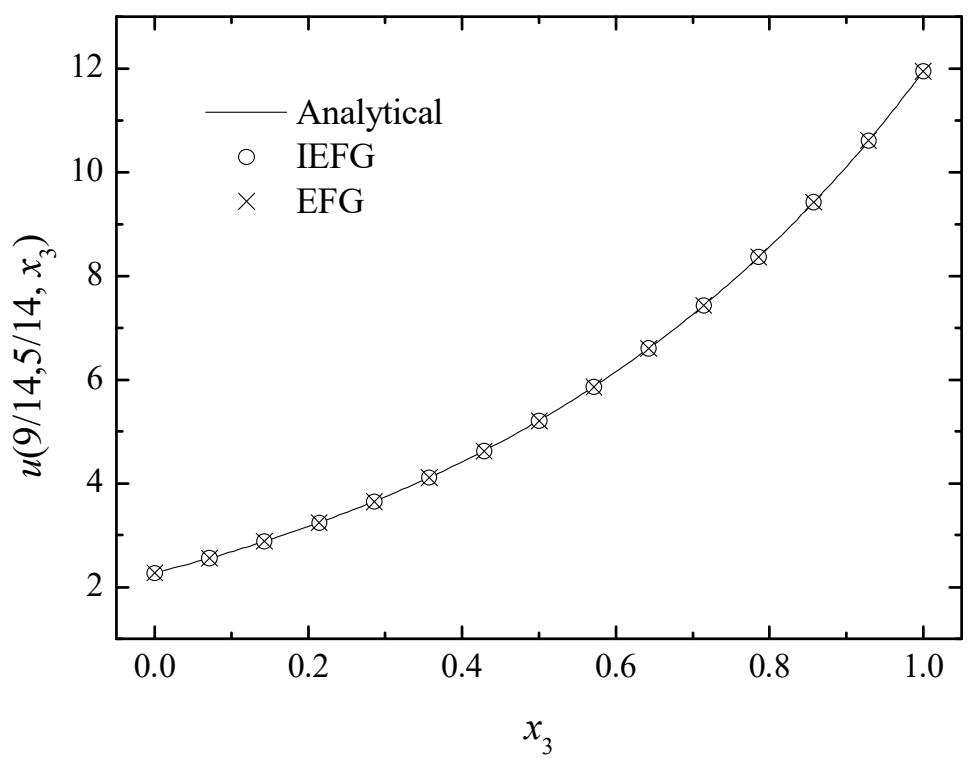

Figure 9. The comparison of the numerical and analytical solutions of the two methods along the $x_{3}$-axis.

When different parameters are selected, $k=5, \xi_{1}=3$, and $\xi_{2}=2.7$. Using two methods to solve it, the same parameters are used. Thus, the relative errors of both methods are equal to $0.5295 \%$. Figures $10-12$ show the comparison of the numerical solutions of the two methods and the analytical ones, and the CPU times of the IEFG method and the EFG method are $92.1 \mathrm{~s}$ and $98.0 \mathrm{~s}$, respectively. We can see that the computational results of both methods are in good agreement with the analytical ones.

We can select $k=10, \xi_{1}=5.8$, and $\xi_{2}=6.2$. Using the two methods to solve it, the same parameters are used, and the relative errors of both methods are equal to $2.3884 \%$. Figures 13-15 show the comparison of the numerical solutions of the two methods and the analytical ones. The computational results of both methods are in good agreement with the analytical ones. 


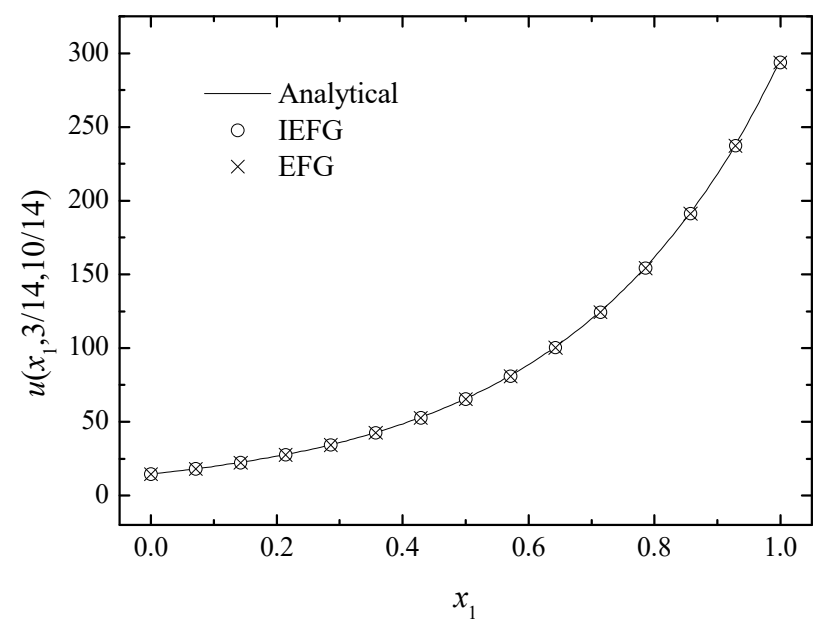

Figure 10. The comparison of the numerical and analytical solutions of the two methods along the $x_{1}$-axis.

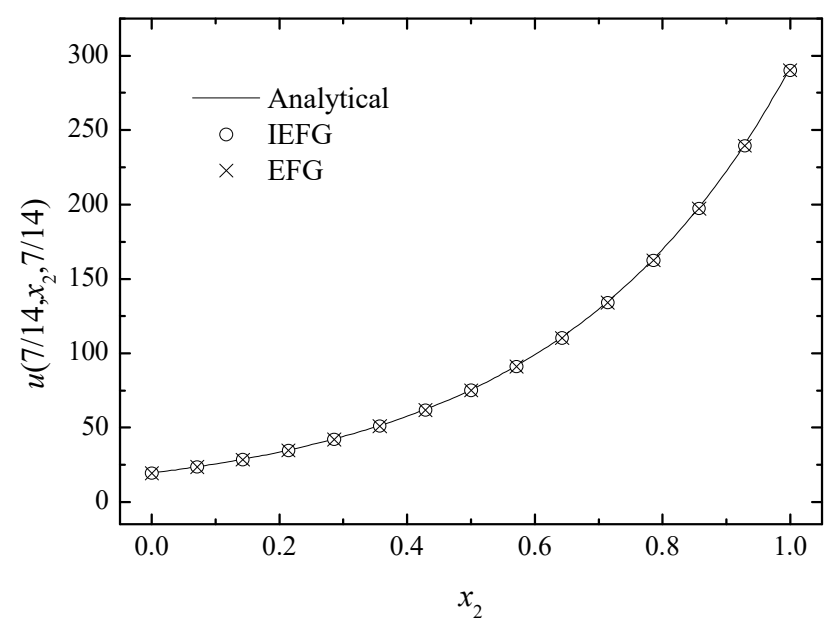

Figure 11. The comparison of the numerical and analytical solutions of the two methods along the $x_{2}$-axis.

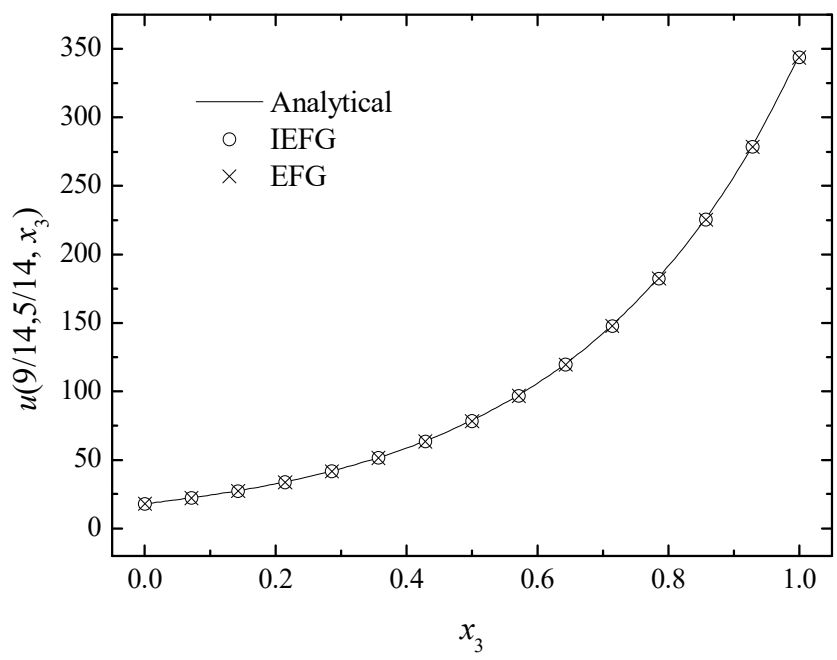

Figure 12. The comparison of the numerical and analytical solutions of the two methods along the $x_{3}$-axis. 


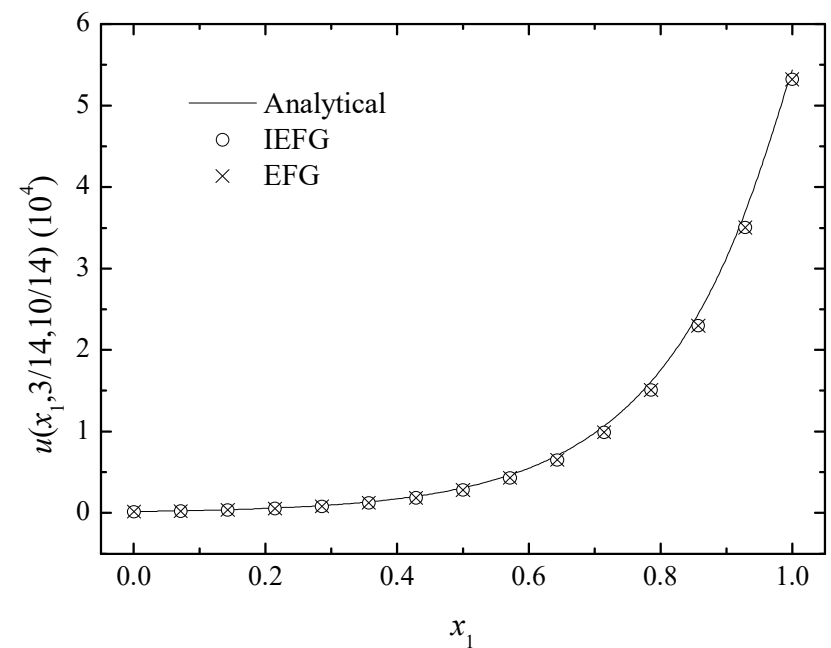

Figure 13. The comparison of the numerical and analytical solutions of the two methods along the $x_{1}$-axis.

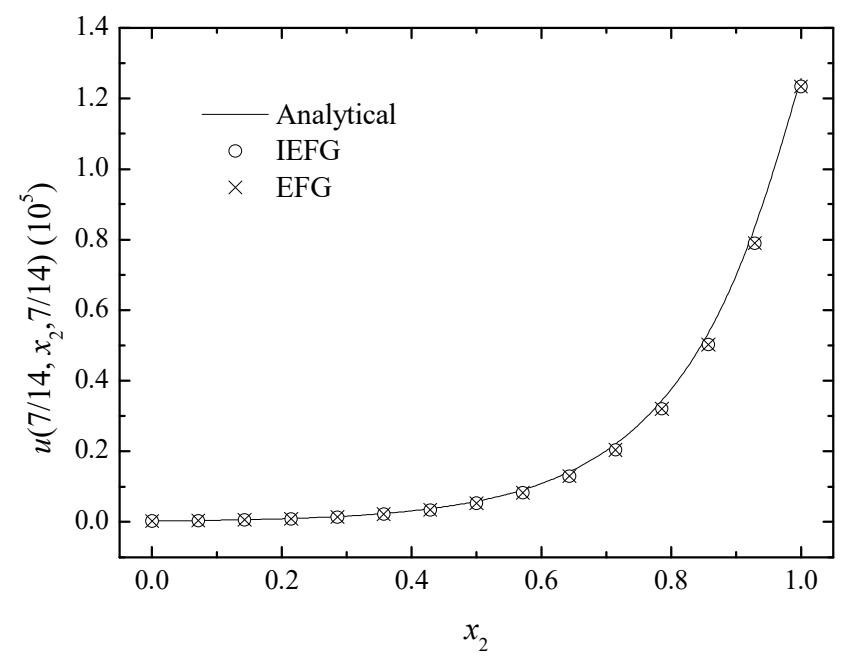

Figure 14. The comparison of the numerical and analytical solutions of the two methods along the $x_{2}$-axis.

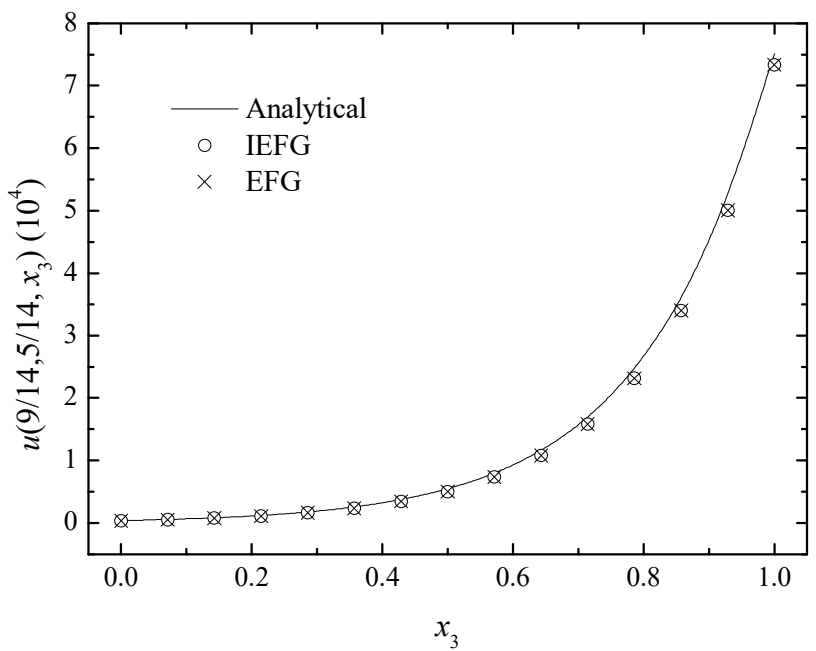

Figure 15. The comparison of the numerical and analytical solutions of the two methods along the $x_{3}$-axis. 
From this example, we can draw two conclusions: On the one hand, the IEFG method has greater computational efficiency; on the other hand, the bigger the wave numbers are, the lower the computational accuracy.

Similarly, if $d_{\max }=1.0$, we select $k=10, \xi_{1}=5.8$, and $\xi_{2}=6.2$. When the EFG method is used, unfortunately, the singular matrix occurs. When the IEFG method is used, the relative error is $2.4229 \%$. The numerical solutions and analytical ones are compared in Figure 16. It is shown that the numerical results are in good agreement with the analytical ones.

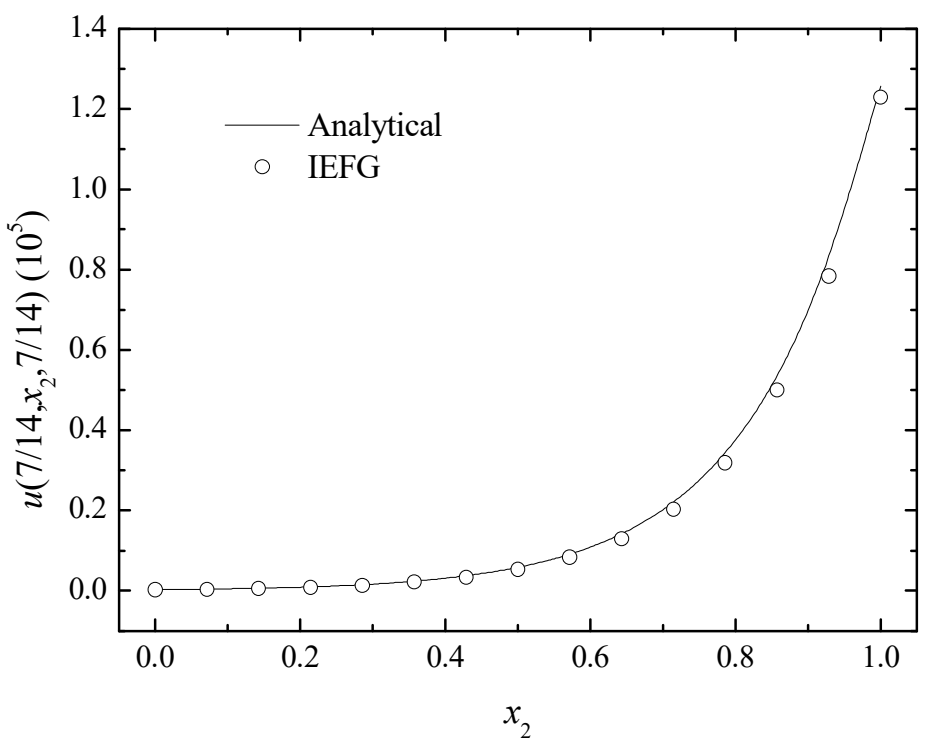

Figure 16. The numerical and analytical solutions of the IEFG method along the $x_{2}$-axis.

The third example [68] is

$$
\Delta u+k^{2} u=\left(k^{2}-3 \pi^{2}\right) \cos \left(\pi x_{1}\right) \sin \left(\pi x_{2}\right) \sin \left(\pi x_{3}\right) .
$$

The boundary conditions are

$$
\begin{gathered}
\frac{\partial u\left(0, x_{2}, x_{3}\right)}{\partial x_{1}}=\frac{\partial u\left(1, x_{2}, x_{3}\right)}{\partial x_{1}}=0, \\
u\left(x_{1}, 0, x_{3}\right)=u\left(x_{1}, 1, x_{3}\right)=0, \\
u\left(x_{1}, x_{2}, 0\right)=u\left(x_{1}, x_{2}, 1\right)=0 .
\end{gathered}
$$

The problem domain is $\Omega=[0,1] \times[0,1] \times[0,1]$, and

$$
u=\cos \left(\pi x_{1}\right) \sin \left(\pi x_{2}\right) \sin \left(\pi x_{3}\right)
$$

is the analytical solution.

The IEFG method is used to solved it. The wave number is selected as 100 , and $19 \times 19 \times 19$ regularly distributed nodes and $18 \times 18 \times 18$ background integral cells are used, $\alpha=1.9 \times 10^{7}, d_{\max }=1.1$. When using the EFG method to solve it, the same parameters are selected, and the relative errors of both methods are equal to $0.8646 \%$. Figures 17-19 show the comparison of the numerical solutions and the analytical ones. We can see that numerical solutions are in good agreement with the analytical ones. The CPU times of the IEFG method and the EFG method are $200.6 \mathrm{~s}$ and $208.1 \mathrm{~s}$, respectively. 


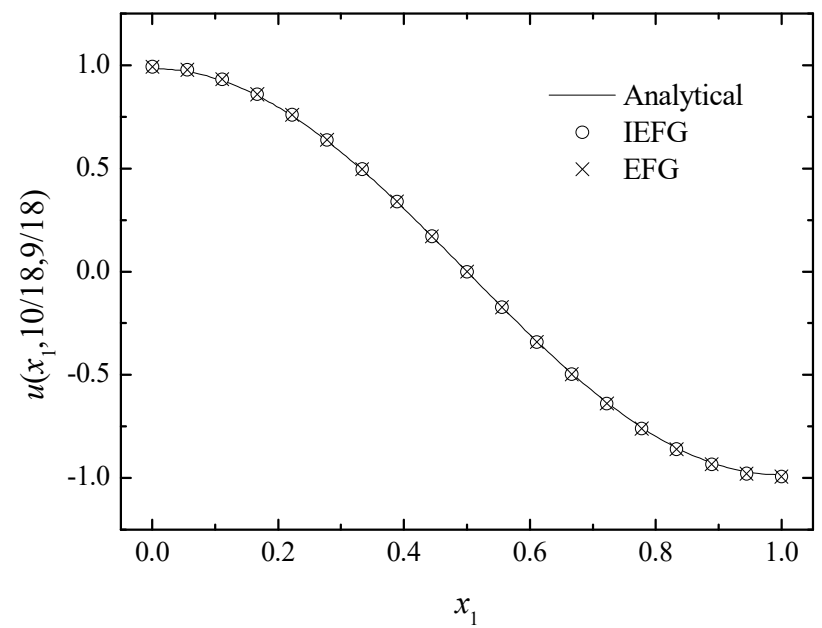

Figure 17. The comparison of the numerical and analytical solutions of the two methods along the $x_{1}$-axis.

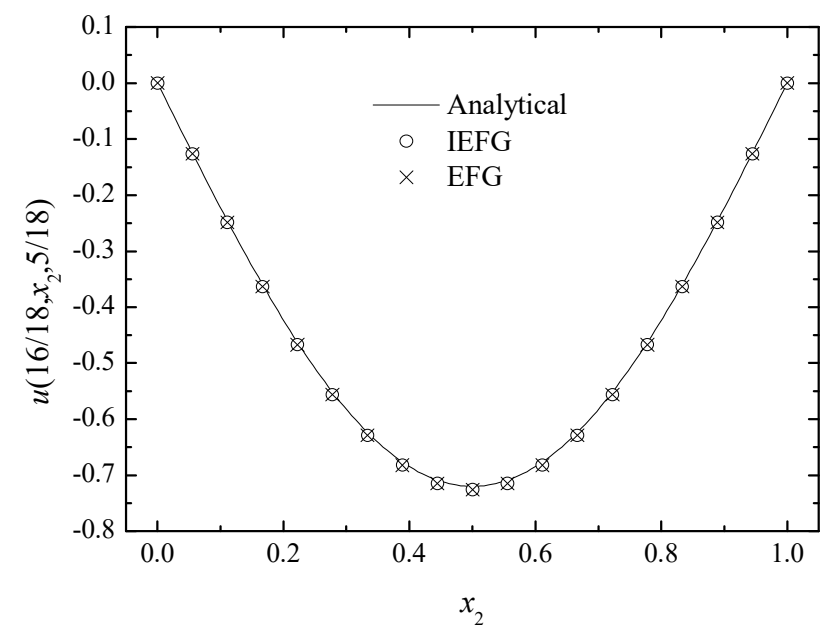

Figure 18. The comparison of the numerical and analytical solutions of the two methods along the $x_{2}$-axis.

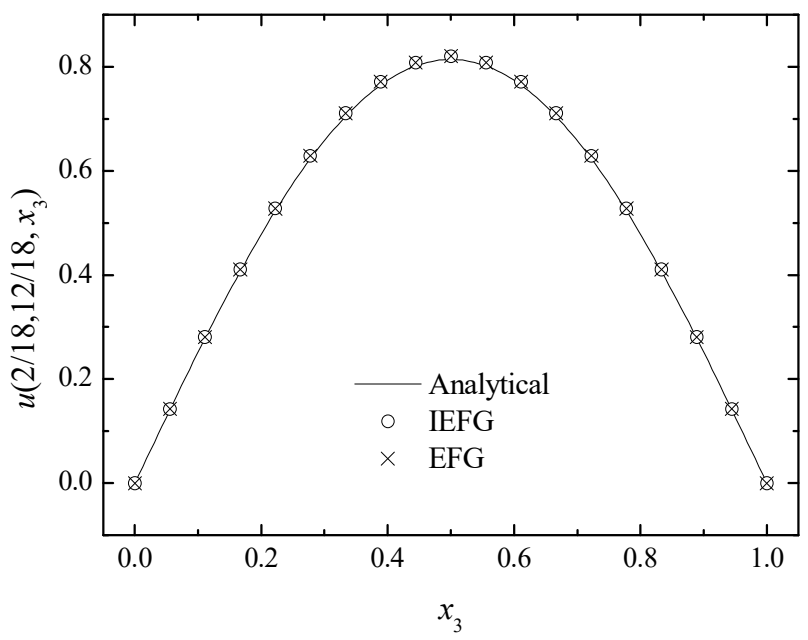

Figure 19. The comparison of the numerical and analytical solutions of the two methods along the $x_{3}$-axis. 
A similar computational accuracy can be obtained when using the two methods, but the higher computational speed can be obtained when using the IEFG method.

Similarly, if $d_{\max }=1.0$, when the EFG method is used, the singular matrix occurs and the final result cannot be obtained. However, when the IEFG method is selected, the relative error is $0.8648 \%$. The numerical solutions and the analytical one are compared in Figure 20, where it is shown that the numerical results are in good agreement with the analytical ones.

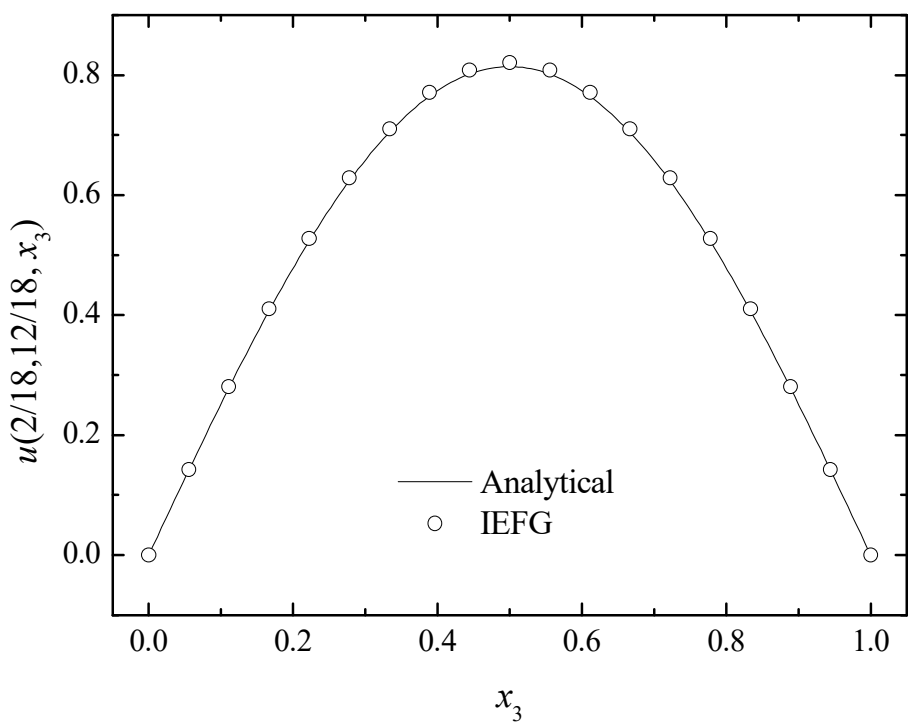

Figure 20. The numerical and analytical solutions of the IEFG method along the $x_{3}$-axis.

\section{Conclusions}

In order to solve 3D Helmholtz equations efficiently, the IEFG method is proposed in this paper.

Some numerical examples are given in Section 4 , and the convergence of the IEFG method is proven numerically. From these examples, we can see that the IEFG method in this paper can not only enhance the computational speed of the traditional EFG method, but also eliminate the phenomenon of the singular matrix.

Author Contributions: Conceptualization, M.P.; methodology, M.P.; software, H.C.; writing-original draft preparation, H.C.; writing-review and editing, M.P.; visualization, H.C.; supervision, M.P.; funding acquisition, H.C. All authors have read and agreed to the published version of the manuscript.

Funding: This research was funded by the Science and Technology Innovation Project of Shanxi Colleges and Universities (grant number 2020L0344) and the Scientific Research Foundation of Taiyuan University of Science and Technology (grant number 20202065).

Institutional Review Board Statement: Not applicable.

Informed Consent Statement: Not applicable.

Data Availability Statement: Not applicable.

Conflicts of Interest: The authors declare no conflict of interest.

\section{References}

1. Bouillarda, P.H.; Suleaub, S. Element-Free Galerkin solutions for Helmholtz problems: Formulation and numerical assessment of the pollution effect. Comput. Methods Appl. Mech. Eng. 1998, 162, 317-335. [CrossRef]

2. Zeng, H.; Peng, L.; Zhao, G.; Han, C. A meshless Galerkin least-square method for the Helmholtz equation. Eng. Anal. Bound. Elem. 2011, 35, 868-878.

3. Miao, Y.; Wang, Y.; Wang, Y.H. A meshless hybrid boundary-node method for Helmholtz problems. Eng. Anal. Bound. Elem. 2009, 33, 120-127. [CrossRef] 
4. Chen, L.C.; Liu, X.; Li, X.L. The boundary element-free method for 2D interior and exterior Helmholtz problems. Comput. Math. Appl. 2019, 77, 846-864.

5. Li, X.L.; Zhang, S.G.; Wang, Y.; Chen, H. A complex variable boundary element-free method for potential and Helmholtz problems in three dimensions. Int. J. Comput. Methods 2020, 17, 1850129. [CrossRef]

6. Chen, L.C.; Li, X.L. A complex variable boundary element-free method for the Helmholtz equation using regularized combined field integral equations. Appl. Math. Lett. 2020, 101, 106067. [CrossRef]

7. Savovic, S.; Djordjevich, A. Numerical solution of diffusion equation describing the flow of radon through concrete. Appl. Radiat. Isot. 2008, 66, 552-555. [CrossRef] [PubMed]

8. Ashyralyev, A.; Aggez, N. Finite Difference Method for Hyperbolic Equations with the Nonlocal Integral Condition. Discret. Dyn. Nat. Soc. 2011, 2011, 562385. [CrossRef]

9. Ivanovic, M.; Svicevic, M.; Savovic, S. Numerical solution of Stefan problem with variable space grid method based on mixed finite element/finite difference approach. Int. J. Numer. Methods Heat Fluid Flow 2017, 27, 2682-2695. [CrossRef]

10. Sowmiya, G.K.; Revathi, M. Numerical Method of Linear Hyperbolic Partial Differential Equation by Finite Difference Method with Conservation Law. Int. J. Adv. Sci. Technol. 2020, 29, 14-23.

11. Thounthong, P.; Khan, M.N.; Hussain, I.; Ahmad, I.; Kumam, P. Symmetric radial basis function method for simulation of elliptic partial differential equations. Mathematics 2018, 6, 327. [CrossRef]

12. Ahmad, I.; Ahsan, M.; Din, Z.U.; Ahmad, M.; Kumam, P. An efficient local formulation for time-dependent PDEs. Mathematics 2019, 7, 216. [CrossRef]

13. Ahmad, I.; Ahmad, H.; Thounthong, P.; Chu, Y.M.; Cesarano, C. Solution of multi-term time-fractional PDE models arising in mathematical biology and physics by local meshless method. Symmetry 2020, 12, 1195. [CrossRef]

14. Wang, F.Z.; Zheng, K.H.; Ahmad, I.; Ahmad, H. Gaussian radial basis functions method for linear and nonlinear convectiondiffusion models in physical phenomen. Open Phys. 2021, 19, 69-76. [CrossRef]

15. Dai, B.D.; Cheng, Y.M. Local boundary integral equation method based on radial basis functions for potential problems. Acta Phys. Sin. 2007, 56, 597-603.

16. Belytschko, T.; Lu, Y.Y.; Gu, L. Element-free Galerkin Methods. Int. J. Numer. Methods Eng. 1994, 37, 229-256. [CrossRef]

17. Cheng, R.J.; Cheng, Y.M. Error estimates of element-free Galerkin method for potential problems. Acta Phys. Sin. 2008, 57, 6037-6046.

18. Cheng, J. Residential land leasing and price under public land ownership. J. Urban Plan. Dev. 2021, 147, 05021009. [CrossRef]

19. Cheng, J. Analysis of commercial land leasing of the district governments of Beijing in China. Land Use Policy 2021, 100, 104881. [CrossRef]

20. Cheng, J. Analyzing the factors influencing the choice of the government on leasing different types of land uses: Evidence from Shanghai of China. Land Use Policy 2020, 90, 104303. [CrossRef]

21. Cheng, J. Data analysis of the factors influencing the industrial land leasing in Shanghai based on mathematical models. Math. Probl. Eng. 2020, 2020, 9346863. [CrossRef]

22. Cheng, J. Mathematical models and data analysis of residential land leasing behavior of district governments of Beijing in China. Mathematics 2021, 9, 2314. [CrossRef]

23. Cheng, Y.M.; Chen, M.J. A boundary element-free method for linear elasticity. Acta Mech. Sin. 2003, 35, 181-186.

24. Zhang, Z.; Zhao, P.; Liew, K.M. Analyzing three-dimensional potential problems with the improved element-free Galerkin method. Comput. Mech. 2009, 44, 273-284. [CrossRef]

25. Zhang, Z.; Wang, J.F.; Cheng, Y.M.; Liew, K.M. The improved element-free Galerkin method for three-dimensional transient heat conduction problems. Sci. China Phys. Mech. Astron. 2013, 56, 1568-1580. [CrossRef]

26. Zhang, Z.; Li, D.M.; Cheng, Y.M.; Liew, K.M. The improved element-free Galerkin method for three-dimensional wave equation. Acta Mech. Sin. 2012, 28, 808-818. [CrossRef]

27. Cheng, R.J.; Cheng, Y.M. Solving unsteady Schrödinger equation using the improved element-free Galerkin method. Chin. Phys. $B$ 2016, 25, 020203. [CrossRef]

28. Cheng, H.; Zheng, G.D. Analyzing 3D advection-diffusion problems by using the improved element-free Galerkin method. Math. Probl. Eng. 2020, 2020, 4317538. [CrossRef]

29. Zhang, Z.; Hao, S.Y.; Liew, K.M.; Cheng, Y.M. The improved element-free Galerkin method for two-dimensional elastodynamics problems. Eng. Anal. Bound. Elem. 2013, 37, 1576-1584. [CrossRef]

30. Yu, S.Y.; Peng, M.J.; Cheng, H.; Cheng, Y.M. The improved element-free Galerkin method for three-dimensional elastoplasticity problems. Eng. Anal. Bound. Elem. 2019, 104, 215-224. [CrossRef]

31. Peng, M.J.; Li, R.X.; Cheng, Y.M. Analyzing three-dimensional viscoelasticity problems via the improved element-free Galerkin (IEFG) method. Eng. Anal. Bound. Elem. 2014, 40, 104-113. [CrossRef]

32. Zheng, G.D.; Cheng, Y.M. The improved element-free Galerkin method for diffusional drug release problems. Int. J. Appl. Mech. 2020, 12, 2050096. [CrossRef]

33. Zhang, Z.; Liew, K.M.; Cheng, Y.M.; Lee, Y.Y. Analyzing 2D fracture problems with the improved element-free Galerkin method. Eng. Anal. Bound. Elem. 2008, 32, 241-250. [CrossRef]

34. Cai, X.J.; Peng, M.J.; Cheng, Y.M. The improved element-free Galerkin method for elastoplasticity large deformation problems. Sci. Sin. Phys. Mech. Astron. 2018, 48, 024701. [CrossRef] 
35. Lancaster, P.; Salkauskas, K. Surfaces generated by moving least squares methods. Math. Comput. 1981, 37, 141-158. [CrossRef]

36. Ren, H.P.; Cheng, Y.M.; Zhang, W. Researches on the improved interpolating moving least-squares method. Chin. J. Eng. Math. 2010, 27, 1021-1029.

37. Ren, H.P.; Cheng, Y.M. The interpolating element-free Galerkin (IEFG) method for two-dimensional potential problems. Eng. Anal. Bound. Elem. 2012, 36, 873-880. [CrossRef]

38. Liu, D.; Cheng, Y.M. The interpolating element-free Galerkin method for three-dimensional transient heat conduction problems. Results Phys. 2020, 19, 103477. [CrossRef]

39. Wu, Q.; Liu, F.B.; Cheng, Y.M. The interpolating element-free Galerkin method for three-dimensional elastoplasticity problems. Eng. Anal. Bound. Elem. 2020, 115, 156-167. [CrossRef]

40. Wu, Q.; Peng, P.P.; Cheng, Y.M. The interpolating element-free Galerkin method for elastic large deformation problems. Sci. China Technol. Sci. 2021, 64, 364-374. [CrossRef]

41. Cheng, Y.M.; Bai, F.N.; Liu, C.; Peng, M.J. Analyzing nonlinear large deformation with an improved element-free Galerkin method via the interpolating moving least-squares method. Int. J. Comput. Mater. Sci. Eng. 2016, 5, 1650023.

42. Qin, Y.X.; Li, Q.Y.; Du, H.X. Interpolating smoothed particle method for elastic axisymmetrical problem. Int. J. Appl. Mech. 2017, 9, 1750022. [CrossRef]

43. Wang, J.F.; Sun, F.X.; Cheng, Y.M. An improved interpolating element-free Galerkin method with nonsingular weight function for two-dimensional potential problems. Chin. Phys. B 2012, 21, 090204. [CrossRef]

44. Liu, F.B.; Cheng, Y.M. The improved element-free Galerkin method based on the nonsingular weight functions for elastic large deformation problems. Int. J. Comput. Mater. Sci. Eng. 2018, 7, 1850023. [CrossRef]

45. Liu, F.B.; Wu, Q.; Cheng, Y.M. A meshless method based on the nonsingular weight functions for elastoplastic large deformation problems. Int. J. Appl. Mech. 2019, 11, 1950006. [CrossRef]

46. Liu, F.B.; Cheng, Y.M. The improved element-free Galerkin method based on the nonsingular weight functions for inhomogeneous swelling of polymer gels. Int. J. Appl. Mech. 2018, 10, 1850047. [CrossRef]

47. Cheng, Y.M.; Peng, M.J.; Li, J.H. The complex variable moving least-square approximation and its application. Acta Mech. Sin. 2005, 37, 719-723.

48. Peng, M.J.; Liu, P.; Cheng, Y.M. The complex variable element-free Galerkin (CVEFG) method for two-dimensional elasticity problems. Int. J. Appl. Mech. 2009, 1, 367-385. [CrossRef]

49. Bai, F.N.; Li, D.M.; Wang, J.F.; Cheng, Y.M. An improved complex variable element-free Galerkin method for two-dimensional elasticity problems. Chin. Phys. B 2012, 21, 020204. [CrossRef]

50. Chen, L.; Cheng, Y.M. Reproducing kernel particle method with complex variables for elasticity. Acta Phys. Sin. 2008, 57, 1-10. [CrossRef]

51. Chen, L.; Cheng, Y.M. The complex variable reproducing kernel particle method for elasto-plasticity problems. Sci. China Phys. Mech. Astron. 2010, 53, 954-965. [CrossRef]

52. Cheng, H.; Peng, M.J.; Cheng, Y.M. The dimension splitting and improved complex variable element-free Galerkin method for 3-dimensional transient heat conduction problems. Int. J. Numer. Methods Eng. 2018, 114, 321-345. [CrossRef]

53. Cheng, H.; Peng, M.J.; Cheng, Y.M. A hybrid improved complex variable element-free Galerkin method for three-dimensional potential problems. Eng. Anal. Bound. Elem. 2017, 84, 52-62. [CrossRef]

54. Cheng, H.; Peng, M.J.; Cheng, Y.M. A fast complex variable element-free Galerkin method for three-dimensional wave propagation problems. Int. J. Appl. Mech. 2017, 9, 1750090. [CrossRef]

55. Cheng, H.; Peng, M.J.; Cheng, Y.M. A hybrid improved complex variable element-free Galerkin method for three-dimensional advection-diffusion problems. Eng. Anal. Bound. Elem. 2018, 97, 39-54. [CrossRef]

56. Cheng, H.; Peng, M.J.; Cheng, Y.M.; Meng, Z.J. The hybrid complex variable element-free Galerkin method for 3D elasticity problems. Eng. Struct. 2020, 219, 110835. [CrossRef]

57. Meng, Z.J.; Cheng, H.; Ma, L.D.; Cheng, Y.M. The dimension split element-free Galerkin method for three-dimensional potential problems. Acta Mech. Sin. 2018, 34, 462-474. [CrossRef]

58. Meng, Z.J.; Cheng, H.; Ma, L.D.; Cheng, Y.M. The dimension splitting element-free Galerkin method for 3D transient heat conduction problems. Sci. China Phys. Mech. Astron. 2019, 62, 040711. [CrossRef]

59. Meng, Z.J.; Cheng, H.; Ma, L.D.; Cheng, Y.M. The hybrid element-free Galerkin method for three-dimensional wave propagation problems. Int. J. Numer. Methods Eng. 2019, 117, 15-37. [CrossRef]

60. Ma, L.D.; Meng, Z.J.; Chai, J.F.; Cheng, Y.M. Analyzing 3D advection-diffusion problems by using the dimension splitting element-free Galerkin method. Eng. Anal. Bound. Elem. 2020, 111, 167-177. [CrossRef]

61. Peng, P.P.; Wu, Q.; Cheng, Y.M. The dimension splitting reproducing kernel particle method for three-dimensional potential problems. Int. J. Numer. Methods Eng. 2020, 121, 146-164. [CrossRef]

62. Peng, P.P.; Cheng, Y.M. Analyzing three-dimensional transient heat conduction problems with the dimension splitting reproducing kernel particle method. Eng. Anal. Bound. Elem. 2020, 121, 180-191. [CrossRef]

63. Peng, P.P.; Cheng, Y.M. Analyzing three-dimensional wave propagation with the hybrid reproducing kernel particle method based on the dimension splitting method. Eng. Comput. 2021, 1-17. [CrossRef]

64. Peng, P.P.; Cheng, Y.M. A hybrid reproducing kernel particle method for three-dimensional advection-diffusion problems. Int. J. Appl. Mech. 2021, 13, 2150085. [CrossRef] 
65. Wu, Q.; Peng, M.J.; Cheng, Y.M. The interpolating dimension splitting element-free Galerkin method for 3D potential problems. Eng. Comput. 2021, 1-15. [CrossRef]

66. Wang, J.F.; Sun, F.X. A hybrid generalized interpolated element-free Galerkin method for Stokes problems. Eng. Anal. Bound. Elem. 2020, 111, 88-100. [CrossRef]

67. Marin, L. A meshless method for the numerical solution of the Cauchy problem associated with three-dimensional Helmholtz-type equations. Appl. Math. Comput. 2005, 165, 274-355. [CrossRef]

68. Cheng, D.S.; Chen, B.W.; Chen, X.L. A robust optimal finite difference scheme for the three-dimensional Helmholtz equation. Math. Probl. Eng. 2019, 2019, 8532408. [CrossRef] 